\title{
Linguistic competence and academic performance in English of grade 11 students in Sta. Teresa College
}

Lozano, Jhomar B. $\square$

Our Lady of Caysasay Academy, Philippines (jhomarbuensalida.lozano@gmail.com)

Ilagan, Allyssa

St. Mary's Educational Institute, Philippines (ilagan.allyssa0416@gmail.com)

Maluluyon, Laiza Jaka A.

Philippines (maluluyonlaizajaka@gmail.com)

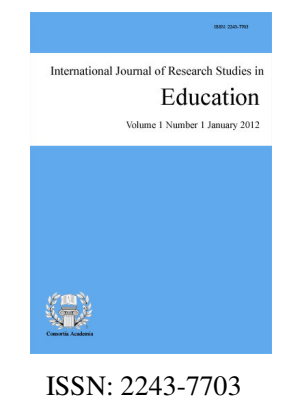

OPEN ACCESS

\section{Abstract}

Linguistic Competence also known as Language Performance is the subconscious knowledge possessed by the native speakers in order to apprehend and unfold the sounds, meaning, language, and pattern in constructing words, phrases and sentences that could relate to the academic performance of an individual. In the field of education, it focused on how the learners apply their learning, specifically in English subjects, that enhance the macro skills of the students. With that, they need to assess in order to develop the process of teaching and learning. In line with that, the authors conducted a study that aims to determine the relationship of linguistic competence and academic performance in English subjects of Grade 11 students. The type of research being utilized in the study was descriptive since analyzing and interpreting the results were needed. In terms of identifying students' linguistic competence dealing with phonology, morphology, semantic and syntax, Linguistic Competence Test was administered. The scores of each learner were transmuted through and by the use of DepEd Order no.8, s. 2015, or the Grade Transmutation Table for K-12 Basic Education Department Program. The students' permanent record was used to determine students' performance in English subjects. Based on the gathered data, the findings states that linguistic competence has a significant relationship with the students' academic performance in English subjects. So, as to improve their level of linguistic competence, enhancement activities were proposed.

Keywords: linguistic competence; phonology; morphology; semantics; syntax; oral communication; reading and writing skills; enhancement activities 


\section{Linguistic competence and academic performance in English of grade 11 students in Sta. Teresa College}

\section{Introduction}

Due to this ever dynamic world, all have already adapted and engaged themselves in speaking English. The only language which is undeniably a prime necessity for communication for it is believed to be the universal language in this world. English has emerged as the universal language which is widely used in different specialism and by different professionals. People who speak and write in the language of English tend to criticize one's utterances and write-ups. Communication is a vital aspect that connects people. Lifelong-learning is a commitment that makes an individual learn and master the language since it is arbitrary. Language keeps on changing. It involves learning all throughout the formative years until the age of refinement to be able to actively participate in the demands and needs of the society. Therefore, the stepping stone through which communication will be developed is starting with grammar, vocabulary, syntax and sentence structure which is best highlighted through linguistic competence.

Meanwhile, this level of linguistic competence in the Philippine Educational setting adheres to the underlying philosophy of "assessment for learning" rather than "assessment of learning" per se: students are assessed in order to enhance the teaching-learning process guided by the principle that education is a life-long activity. Assessment of learning, however, is the building block that is introduced in the Philippine school. Furthermore, it was also highly observable that they encountered difficulties with regard to the use of words, sentence structure of their self-composed paragraphs and struggled in the lexicon. This talks about the areas of linguistic competence which are phonology (deals with sounds), morphology (concerns with the word construction and its usage), semantics (meaning of a phrase, sentence or even a larger unit) and syntax (regards with the sentence structure, correctness of grammar and other syntactical concerns).

In connection with this, linguistic awareness in writing, the researchers delved in studying the possible consequence that can be related to it. One of which that the researchers considered to greatly affect was the academic performance of the students in English subjects such as Oral Communication and Reading and Writing Skills. Mainly, this study sought to resolve the issues concerning the Linguistic Competence and Academic Performance of Grade 11 Students in English subjects such as: Oral Communication and Reading and Writing Skills, in Sta. Teresa College. Moreover, this also intended to identify whether the level of linguistic competence had a relationship to the academic performance of the Grade 11 students in English subjects such as: Oral Communication and Reading and Writing Skills, so as to provide enhancement activities that will supplement the gaps arising to produce competent citizens.

\section{Literature review}

\subsection{Linguistic competence}

Linguistic competence is the ability to understand and use the language considering the technical rules that it encompasses in a communication. As mentioned by Pearson and associates (2008) noted that language can be described as the most effective means of human communication. It is where communication in general can be defined as the transmission of information between a source and a receiver by means of signs. Moreover, Pearson and associates (2008) also cited that human beings communicate in lots of ways, but the most effective way of communication is linguistic communication, through the use of language. The basic signs used in linguistic communication are words. 
Linguistic Competence is the knowing on how to use the grammar, syntax and vocabulary of a language. Linguistic competence asks about the words to be used and how to put these words into phrases and sentences. It is the mastery of the linguistic code, the ability to recognize the lexical, morphological (meaning-bearing units of a language), syntactical and phonological (sound) features of a language and to manipulate these features to form words and sentences demonstrated by the ability to use a rule not to state a rule.

According to Magboo (2015), linguistic competence is a tool towards communication which is the symbiotic interaction of two or more persons. If communication is to occur, a certain stimulus will be sent and received. Thus, the sender of the message must be efficient and proficient enough to convey the message as intelligible as possible so that it will be correctly understood and will make sense. While according to Faarlund, Cappelen, and Wilson (2012), linguistic competence addresses three interconnected sets of issues about the kinds of competence that underlie linguistic agency. The first centers on the question of whether linguistic agency exhibits a kind of knowing-how. The second addresses issues having to do with knowledge of word meaning. The third addresses questions about syntactic competence and its acquisition.

Language competence is a term which includes the linguistics or grammatical competence, discourse competence, sociolinguistics competence and what might be called as textual competence. Language competence refers to the knowledge of a language, cognitive aspect in learning a language, and of course the ability to use that language to produce meaningful production and language performance. Competence is used to describe the learner's capacity to produce a language. Kashyap (2012) cited Chomsky who explained that linguistic competence is the knowing of how to use the grammar, syntax and vocabulary of a language. Such asks: What words do I use? How do I put them into phrases and sentences? It defines the system of rules that governs an individual's tacit understanding of what is acceptable and what is not in the language they speak. While, Richard and Schimdt (2010) discussed that Language proficiency is the degree of skill with which a person can use the language, such as how well a person can read, write speak or understand language. This can be contrasted to the language achievement, which describes language ability as a result of learning. Proficiency may be measured through the use of proficiency test.

Phonology - Phonology refers both to the linguistic knowledge that speakers have about the sound patterns of their language and to the description of that knowledge that linguists try to produce. Thus it is like the way we defined grammar as your mental knowledge of your language, or a linguist's description of that knowledge. Knowledge in Phonology determines how we pronounce words and the parts of words we call morphemes. Often, certain morphemes are pronounced differently depending on their context, and we will introduce a way of describing this variation with phonological rules. We begin with some examples from English, and then move on to examples from other languages (Fromkin, Rodman, \& Hyams, 2010). While, Cabantac (2011) argued that grammatical knowledge is not enough. It is affected by the socio-cultural relation including the attitude, values, conventions, prejudices and preferences of the people who use the language; the nature of the participants which shows the relationship between the speaker and the listener, their occupation, interest, socio-economic status, etc.; the mode (medium) of communication, whether spoken or written form or reading from a written script, or unprepared speech.

Morphology - Words are an important part of linguistic knowledge and constitute a component of our mental grammars, but one can learn thousands of words in a language and still not know the language. Anyone who has tried to communicate in a foreign country by merely using a dictionary knows this is true. On the other hand, without words we would be unable to convey our thoughts through language or understand the thoughts of others. Because each word is a sound-meaning unit, each word stored in our mental lexicon must be listed with its unique phonological representation, which determines its pronunciation, and with a meaning. Each word in your mental lexicon includes other information as well, such as whether it is a noun, pronoun, verb, adjective, adverb, preposition or a conjunction. That is, the mental lexicon also specifies the grammatical category or syntactic class of the word. If such information were not in the mental lexicon, we would not know how to form grammatical sentence, nor would we be to distinguish grammatical from ungrammatical sentences. The study of 
the internal structure of words, and of the rules by which words are formed, is morphology. This world itself consists of two morphemes, morph + ology, and the suffix -ology, means "science of" or "branch of knowledge concerning". Thus, the meaning of morphology is "the science of (word) forms. Morphology is part of our grammatical knowledge of a language. Like most linguistic knowledge, this is generally unconscious knowledge (Fromkin, Rodman, \& Hyams, 2010).

Semantics - It denotes a range of ideas, from the popular to the highly technical. It is often used in ordinary language to denote a problem of understanding that comes down to a word selection or connotation. This problem of understanding has been subject of formal inquiries, over a long period of time, most notably in the field of formal semantics. In linguistics, it is the study of interpretation of signs or symbols as used by agents or communities within the particular circumstances and contexts (Chomsky, 2012 as cited by Cabral, 2012). Furthermore, Knowing the meaning of a sentence, then, means knowing under what circumstances it would be true or false according to your knowledge of the world, namely its truth conditions. Reducing the questions of meaning to the question of truth conditions has proved to be very fruitful in understanding the semantic properties of language. Our semantic knowledge tells us when words or phrases (including sentences) have more than one meaning, that is, when they are ambiguous. Lexical ambiguity arises when at least one word in a phrase has more than one meaning. Our knowledge of lexical and structural ambiguities reveals that the meaning of a linguistic expression is built both on the words it contains and its syntactic structure. To account for speakers' knowledge of grammatically, constituent structure, and relations between sentences, as well as for the limitless creativity of our linguistic competence, we concluded that the grammar must contain syntactic rules. To account for speaker's knowledge of the truth, reference, entailment and ambiguity of sentences, as well as for our ability to determine the meaning of a limitless number of expressions, we must suppose that the grammar contains semantic rules that combine the meanings of words into meaningful phrases and sentences. Our semantic rules must be sensitive not only to the meaning of individuals but to the structure in which they occur (Fromkin, Rodman, \& Hyams, 2010).

Syntax - Another aspect of linguistic competence relates to the nature of linguistic structure, in particular syntax, and its acquisition. The object of inquiry is the linguistic competence of individual speakers or the language and its nature, use and acquisition. This competence is acquired through interplay of the innate language faculty and the social norms of the learning environment. Faarlund and associates (2012), building on their work in the first phase of CSMN, plans to focus their research on two specific issues: (a) the transfer of structural knowledge from one generation to the next and thus through time (diachronic syntax), and (b) the role of the socio-cultural environment in the evolution of language, especially related to the question of linguistic and cultural complexity. In addition, Koll (2012) added that despite what modern eyes appear to be a spelling and grammatical nightmare such writing was and is profound, inspirational and indeed immortal. He even concluded that great writers do not become great because they blindly obey grammar and punctuation rules, they are great because of what they have to say and how they go about saying it. However, Koll (2012) was also contradicting the notion that he is entirely suggesting that developing skills in spelling, grammar and punctuation is unnecessary. He still affirms that mechanical aspects of writing are indeed important, as important as screws and nails holding up the homes and classrooms and developing the associated skills is a vital step to becoming a good writer. But focusing on these skills to the exclusion of all the other aspects of writing (focus, structure, rhetorical strategies, etc.) is like spending all one's money for invaluable things.

\subsection{Academic performance}

Antenor (2009) defined performance as a feature of a curriculum that should be given emphasis. The curriculum is deemed to be successful if the performance is higher than the targets set. However, if the performance of the learners is low then it follows that the curriculum has failed. A good curriculum is one that results in high or excellent performance. Thus, the curriculum should be clear at the beginning with what knowledge, skills and values should be developed by the learners. According to Acurantes (2009), English as one of the subjects being studied in the Philippines contributes greatly to one's success especially when it comes to 
business. It is considered as the second language of the country and the means of communication of different countries to understand in each other. He also assessed that learning English varies from each individual. It could be for personal pursuit of job opportunities. The author cited the different ways on how a teacher can teach English to the students.

Agito (2013) stated that academic performance was said to be an accomplishment which revealed the potential ability of every student and the success of every school. Moreover, this performance in the curriculum is attached by one's motivation. Motivation is an inner drive that causes an individual to do something and persevere at something. It also energizes one to do something toward an action. It initiates, directs and intensifies the persistence of behavior. Many factors affect a given student's motivation to learn. This includes, interest in the subject matter, perception of its usefulness, general desire to achieve, self-confidence and self-esteem, patience and persistence, and, approval of others and some overcoming challenges.

Academic performance refers to the amount of learning gained by the students, measurable in terms of achieved numerical scores with the corresponding transmuted grades. Academic performance refers to how students deal with their studies and how they cope with or accomplish different tasks given to them by their teachers. The variables that affect student's quality of academic achievement are inside and outside school. Series variables are to be considered when to identify the affecting factors towards quality of academic success. Identifying the most contributing variables in quality of academic performance is very complex and challenging job.

\subsection{Enhancement activities}

Many sources have shown that direct instruction isn't the best way to teach your students. A master teacher will find ways to use data to drive creation of student-centered activities. For example, if students achieve a class average of 75 or below on a certain vocabulary test, it can reasonably be assumed that vocabulary activities are areas of weakness. Therefore, standing at tournament, however, where to students compete to match words and definitions on the board in a certain amount of time, likely will achieve your goals. You might divide the classroom into teams or have students compete against each other. This activity is sure to engage even the most reluctant learners.

Activities are often designed to assist students in becoming proficient in English, concurrently with academic development. The objective of the program is integration into the mainstream school program as soon as feasible in order to achieve the learning outcomes. Based on assessed needs, adaptations may be implemented to address the unique learning needs of these students. Some pointed out that objectives are often linked to a view of language learning that sees language proficiency as the sum total of mastering a vast array of discrete items while others suggested that objectives are inappropriate in view of the nature of foreign language learning, since language is creative and unpredictable. She further indicated that objectives are best reserved for lower order skills. Brantley and Miller (2007) added that one's ability to communicate effectively strongly influences one's professional advancement and personal success. In the global marketplace of today, many employers believe that the ability to communicate is the most important job-related skill.

In this study the researchers seek to determine the relationship between the linguistic competence and the academic performance of the Grade 12 students in Sta. Teresa College and answer the following questions:

$>$ What is the level of linguistic competence of the students in terms of phonology, morphology, semantics, and syntax?

$>\quad$ How may the levels of academic performance of the students in Oral Communication and Reading and Writing Skills be described?

$>\quad$ Are there any significant relationships between the levels of linguistic competence and academic performance of the students in Oral Communication and Reading and Writing Skills?

$>$ Based on the findings, what linguistic enhancement activities may be proposed to improve student's linguistic competence? 


\section{Methods and materials}

\subsection{Research design}

This study made use of descriptive design to determine the linguistic competence of Grade 11 students in Sta. Teresa College. Descriptive research is used to obtain factual information about linguistics. The researchers used a linguistic competence test answered by the students. Valdez (2013) cited that descriptive research is concerned with the description of data and characteristics about a population. The goal is the acquisition of factual, accurate and systematic data that can be used in averages, frequencies and similar statistical calculations. Descriptive studies seldom involve experimentation, as they are more concerned with naturally occurring phenomena than with the observation of controlled situations.

\subsection{Respondents}

The respondents of the study were 281 Grade 11 Senior High School students in Sta. Teresa College. Looking at the pie graph, majority of the subjects are from STEM with 208 students having 74.02 or exactly 74 percent. Next to STEM is ABM with 49 of the total number of respondents which equates to 17.43 or 18 percent to be exact. Lastly, 24 students with 8.19 or exactly 8 percent of the total number of respondents are from HUMSS.

\subsection{Instrument}

Construction - In order to measure the linguistic competence of Grade 11 students in Sta. Teresa College, the researchers decided to give them a linguistic competence test. This is a modified test from different standardized tests. At first, it is a 100-item test which composed of the four areas of Linguistics namely: phonology, morphology, semantics and syntax; and having a 25-item each. After being edited, modified and validated, the researchers considered the comments and suggestions of the experts for the revisions to make. After the revisions have been made, the test came to be a 60 -item test, 15 -item per each area of linguistic competence. Table of Specifications can be gleaned on Table 1.

\section{Table 1}

Table of specifications

\begin{tabular}{|c|c|c|}
\hline Area of Linguistic Competence & No. of Items & Percentage \\
\hline Phonology & 15 & 25 \\
\hline Morphology & 15 & 25 \\
\hline Semantics & 15 & 25 \\
\hline Syntax & 15 & 25 \\
\hline Total & 60 & 100 \\
\hline
\end{tabular}

Validation - The researchers made letters to be addressed to different experts, in linguistics and in statistics, to validate the modified test. After being edited, modified and validated, the researchers considered the comments and suggestions of the experts for the revisions to make.

Administration - The researchers together with the school administrators decided to give the test papers to the respective class advisers. The administration of the Linguistic Competence Test will be done right after the taking of the final examination for the inclusive semester.

Scoring - After giving the tests, they were checked and scored by the researchers. The scores were categorized into four areas of linguistics; also, the total score was computed. There is a parameter used that will determine the level of linguistic competence of the respondents. Likewise, the researchers transmuted the initial grade or the raw score of the respondents through and by the use of DepEd Department Order 8, s.2015, seen on Table 2. 
Linguistic competence and academic performance in English of grade 11 students in Sta. Teresa College

Table 2

Grade transmutation table for K-12 Basic Education Program

\begin{tabular}{cccc}
\hline Initial Grade & Transmuted Grade & Initial Grade & Transmuted Grade \\
\hline 100 & 100 & & \\
$98.40-99.99$ & 99 & $66.40-67.99$ & 79 \\
$96.80-98.39$ & 98 & $64.80-66.39$ & 78 \\
$95.20-96.79$ & 97 & $63.20-64.79$ & 76 \\
$93.60-95.19$ & 96 & $61.60-63.19$ & 75 \\
$92.00-93.59$ & 95 & $60.00-61.59$ & 74 \\
$90.40-91.99$ & 94 & $56.00-59.99$ & 73 \\
$88.80-90.39$ & 93 & $52.00-55.99$ & 72 \\
$87.20-88.79$ & 92 & $48.00-51.99$ & 71 \\
$85.60-87.19$ & 91 & $44.00-47.99$ & 70 \\
$84.00-85.59$ & 90 & $40.00-43.99$ & 69 \\
$82.40-83.99$ & 89 & $36.00-39.99$ & 68 \\
$80.80-82.39$ & 88 & $32.00-35.99$ & 67 \\
$79.20-80.79$ & 87 & $28.00-31.99$ & 66 \\
$77.60-79.19$ & 86 & $24.00-27.99$ & 65 \\
$76.00-77.59$ & 85 & $20.00-23.99$ & 64 \\
$74.40-75.99$ & 84 & $16.00-19.99$ & 63 \\
$72.80-74.39$ & 83 & $12.00-15.99$ & 62 \\
$71.20-72.79$ & 82 & $8.00-11.99$ & 61 \\
$69.60-71.19$ & 81 & $4.00-7.99$ & 60 \\
$68.00-69.59$ & 80 & $0-3.99$ & \\
\hline
\end{tabular}

Like on how the researchers measured the linguistic competence of the students, a parameter was used to determine the level of academic performance of the Grade 11 students. It is likewise the scale used to determine the progress and achievement of the learners in $\mathrm{K}$ to 12 Curriculum. Looking at Table 3, this shows the Learner Progress and Achievement scale used to know the level of academic performance of the subject of this study.

Table 3

Learner progress and achievement

\begin{tabular}{lcc}
\hline \multicolumn{1}{c}{ Descriptor } & Grading Scale & Remarks \\
\hline Outstanding & $90-100$ & Passed \\
Very Satisfactory & $85-89$ & Passed \\
Satisfactory & $80-84$ & Passed \\
Fairly Satisfactory & $75-79$ & Passed \\
Did Not Meet Expectations & Below 75 & Failed \\
\hline
\end{tabular}

Statistical Treatment - The researchers used various statistical techniques. (1) Frequency, to determine the number of respondents for each level of linguistic competence and academic performance in core subjects. (2) Weighted Mean, to determine and describe the levels of linguistic competence and academic performance in Oral Communication and Reading and Writing Skills of the Grade 11 students. (3) Percentage, to device the relationship of the frequency of each level of linguistic competence and the academic performance in core subjects. (4) Pearson moment of Correlation (Pearson-r), to determine the degree of relationship between the linguistic competence and the academic performance in core subjects.

\section{Results}

4.1 Level of Linguistic Competence of the Grade 11 Students

Table 4

Level of linguistic competence of the Grade 11 students in terms of phonology

\begin{tabular}{|c|c|c|}
\hline Levels & Frequency & Percentage \\
\hline Outstanding (90-100) & 5 & 1.78 \\
\hline Very Satisfactory (85-89) & 9 & 3.20 \\
\hline Satisfactory $(80-84)$ & 39 & 13.88 \\
\hline Fairly Satisfactory (75-79) & 119 & 42.35 \\
\hline Did Not Meet Expectations (Below 75) & 109 & 38.79 \\
\hline Total & 281 & 100 \\
\hline
\end{tabular}


It can be gleaned in the table that Fairly Satisfactory has the most number of frequencies having 119 with 42.35 percent. It is followed by did not meet Expectations with109 frequency and 38.79 percent. Also, 39 students of the total frequency fell under satisfactory having 13.88 percent. While, 9 students were labelled as very satisfactory that equates to 3.20 percent. Lastly, 5 students from the group were labelled as outstanding with the percentage of 1.78 .

\section{Table 5}

Level of linguistic competence of the Grade 11 students in terms of morphology

\begin{tabular}{|c|c|c|}
\hline Levels & Frequency & Percentage \\
\hline Outstanding (90-100) & 17 & 6.05 \\
\hline Very Satisfactory (85-89) & 26 & 9.25 \\
\hline Satisfactory $(80-84)$ & 24 & 8.55 \\
\hline Fairly Satisfactory (75-79) & 56 & 19.93 \\
\hline Did Not Meet Expectations (Below 75) & 158 & 56.23 \\
\hline Total & 281 & 100 \\
\hline
\end{tabular}

Looking at the table, 158 students or 56.23 percent of the total subjects levelled on did not meet expectations. 56 students or 19.93 percent have fairly satisfactory on a scale of 75-79. While 9.25 percent of the total percentage, having a frequency of 26 students, levelled under very satisfactory. On the other hand, 24 students or 8.55 percent labelled as satisfactory and 6.05 percent with a frequency of 17 fell under the outstanding level.

\section{Table 6}

Level of linguistic competence of the Grade 11 students in terms of semantics

\begin{tabular}{|c|c|c|}
\hline Levels & Frequency & Percentage \\
\hline Outstanding (90-100) & 3 & 1.07 \\
\hline Very Satisfactory $(85-89)$ & 4 & 1.42 \\
\hline Satisfactory (80-84) & 20 & 7.12 \\
\hline Fairly Satisfactory (75-79) & 77 & 27.40 \\
\hline Did Not Meet Expectations (Below 75) & 177 & 62.99 \\
\hline Total & 281 & 100 \\
\hline
\end{tabular}

As shown on the table presented, 177 students which equates to 62.99 percent of the total percentage fell under did not meet expectations. Moreover, at the level fairly satisfactory, there are 77 students who are under the scale of 75-79, which is equivalent to 27.40 percent. Meanwhile, at the level of satisfactory there are 20 students which are 7.12 percent of the total respondents. 4 students fell under as very satisfactory level which is equivalent to 1.42 percent. Lastly, only 3 students having a percentage of 1.07 managed to be labelled as outstanding.

Table 7

Level of linguistic competence of the Grade 11 students in terms of syntax

\begin{tabular}{|c|c|c|}
\hline Levels & Frequency & Percentage \\
\hline Outstanding (90-100) & 0 & 0 \\
\hline Very Satisfactory (85-89) & 1 & 0.35 \\
\hline Satisfactory (80-84) & 6 & 2.14 \\
\hline Fairly Satisfactory (75-79) & 71 & 25.27 \\
\hline Did Not Meet Expectations (Below 75) & 203 & 72.24 \\
\hline Total & 281 & 100 \\
\hline
\end{tabular}

Out of 281 students, 203 fell under did not meet expectations with the percentage of 72.24. It was followed by the fairly satisfactory with 71 students having 25.27 percent. While 6 students with 2.14 percent have fallen under the satisfactory level and there's only a student being labelled as very satisfactory for it has 0.35 percent of the total respondents. No one from the subject managed to be categorized as outstanding. 
Linguistic competence and academic performance in English of grade 11 students in Sta. Teresa College

4.2 Level of Academic Performance of the Grade 11 Students

Table 8

Level of academic performance of the students in oral communication

\begin{tabular}{|c|c|c|}
\hline Levels & Frequency & Percentage \\
\hline Outstanding (90-100) & 27 & 9.61 \\
\hline Very Satisfactory (85-89) & 162 & 57.65 \\
\hline Satisfactory (80-84) & 64 & 22.78 \\
\hline Fairly Satisfactory (75-79) & 28 & 9.96 \\
\hline Did Not Meet Expectations (Below 75) & 0 & 0 \\
\hline Total & 281 & 100 \\
\hline
\end{tabular}

It can be gleaned in the table that, the highest frequency with 162 students having 57.65 percent was in the very satisfactory level. 64 students or 22.78 percent of the total respondents fell under satisfactory level. There are 28 students or 9.96 percent that belongs to fairly satisfactory while, 27 students or 9.61 percent placed under outstanding level. Lastly, there is no one who managed to be labelled under did not meet expectations.

\section{Table 9}

Level of academic performance of the students in reading and writing skills

\begin{tabular}{|c|c|c|}
\hline Levels & Frequency & Percentage \\
\hline Outstanding (90-100) & 116 & 41.29 \\
\hline Very Satisfactory (85-89) & 120 & 42.70 \\
\hline Satisfactory (80-84) & 41 & 14.59 \\
\hline Fairly Satisfactory (75-79) & 4 & 1.42 \\
\hline Did Not Meet Expectations (Below 75) & 0 & 0 \\
\hline Total & 281 & 100 \\
\hline
\end{tabular}

The table above showed that the highest frequency with 120 students having 42.70 percent were in the very satisfactory level. 116 students or 41.29 percent of the total respondents fell under outstanding level. There are 41 students or 14.59 percent that belongs to satisfactory while, 4 students or 1.42 percent placed under outstanding level. Lastly, there is no one who managed to be labelled under Did Not Meet Expectations.

\subsection{Relationship between the Linguistic Competence and Academic Performance of the Grade 11 Students}

\section{Table 10}

Relationship between the level of linguistic competence and academic performance in oral communication

\begin{tabular}{cccccccc}
\hline Variables & Mean & $\begin{array}{c}\text { Mean } \\
\text { Difference }\end{array}$ & $r$-value & $\begin{array}{c}\text { Verbal } \\
\text { Interpretation }\end{array}$ & $p$-value & Decision & $\begin{array}{c}\text { Verbal } \\
\text { Interpretation }\end{array}$ \\
\hline $\begin{array}{c}\text { Linguistic } \\
\text { Competence } \\
\begin{array}{c}\text { Oral } \\
\text { Communication }\end{array}\end{array}$ & 74.00 & 11.44 & 0.568 & Moderate & .000 & Reject Ho & Significant \\
Note. $d f=279, p<.05$. & 85.44 & & & & & \\
\hline
\end{tabular}

Based on the table, it shows that the linguistic competence and the academic performance in Oral Communication have a relationship. This means that the linguistic competence increases the academic performance also increases. If you are to look on the mean of the linguistic competence which is 74 and academic performance which is 85.44 , maybe you'll be having a thought about the result. There are certain factors to be considered that we cannot say that linguistic competence is the only factor that affects the academic performance. Take note that in getting the academic performance in this new curriculum, there are these three components of grading system in core subjects which is considered: Written Works with $25 \%$, Performance Tasks which has 50\% and the rest 25\% is allotted for the Quarterly Assessment, with a total of $100 \%$ percent. 
Lozano, J. B., Ilagan, A., \& Maluluyon, L. J. A.

\section{Table 11}

Relationship between the level of linguistic competence and academic performance in reading and writing skills

\begin{tabular}{cccccccc}
\hline Variables & Mean & $\begin{array}{c}\text { Mean } \\
\text { Difference }\end{array}$ & $r$-value & $\begin{array}{c}\text { Verbal } \\
\text { Interpretation }\end{array}$ & $p$-value & Decision \\
\hline $\begin{array}{c}\text { Linguistic } \\
\begin{array}{c}\text { Competence } \\
\text { Reading }\end{array}\end{array}$ & 74.00 & 14.38 & .570 & Moderate & .000 & Reject Ho & Significant \\
and Writing Skills & 88.38 & & & & & \\
\hline
\end{tabular}

Note. $d f=279, p<.05$.

Based on the table, it shows that the linguistic competence and the academic performance in Reading and Writing Skills have a relationship. This means that as the competence in linguistic increases academic performance also increases. If you are to look on the mean of the linguistic competence which is 74 and academic performance which is 88.38 , maybe you'll be having a thought about the result. There are certain factors to be considered; we cannot say that linguistic competence is the only factor that affects the academic performance. Take note that in getting the academic performance in this new curriculum, there are these three components of grading system in core subjects which is considered: Written Works with 25\%, Performance Tasks which has 50\% and the rest 25\% is allotted for the Quarterly Assessment, with a total of $100 \%$ percent.

\section{Table 12}

Relationship between the areas of linguistic competence and academic performance in oral communication

\begin{tabular}{|c|c|c|c|c|c|c|c|}
\hline Variables & Mean & $\begin{array}{c}\text { Mean } \\
\text { Difference }\end{array}$ & $r$-value & $\begin{array}{c}\text { Verbal } \\
\text { Interpretation }\end{array}$ & $p$-value & Decision & $\begin{array}{c}\text { Verbal } \\
\text { Interpretation }\end{array}$ \\
\hline Phonology & 75.93 & 9.51 & .159 & Very Low & .000 & Reject Ho & Significant \\
\hline Oral communication & 85.44 & & & & & & \\
\hline Morphology & 74.92 & 10.52 & .547 & Moderate & .000 & Reject Ho & Significant \\
\hline Oral communication & 85.44 & & & & & & \\
\hline Semantics & 73.15 & 12.29 & .440 & Moderate & .000 & Reject Ho & Significant \\
\hline Oral communication & 85.44 & & & & & & \\
\hline Syntax & 72.02 & 13.42 & .373 & Low & .000 & Reject Ho & Significant \\
\hline Oral communication & 85.44 & & & & & & \\
\hline
\end{tabular}

Note. $d f=279, p<.05$

The table above presents the relationship between the areas of linguistic competence and academic performance in Oral Communication of the Grade 11 students. The relationship between phonology and academic performance in Oral Communication has a computed $r$-value of .159 , which has the verbal interpretation of very low correlation. On the other hand, morphology and academic performance in Oral Communication got .547 and semantics with $r$-value .440 which was labelled as moderate correlation. Lastly syntax with $r$-value of .373 has low correlation with the academic performance. This means that phonology has a relationship with the students' academic performance for only at least. The table shows that morphology and semantics affect most in the academic performance of the students, since it has moderate correlation. Syntax, as shown in the table, has low correlation which means, it affects averagely.

\section{Table 13}

Relationship between the areas of linguistic competence and academic performance in reading and writing skills

\begin{tabular}{|c|c|c|c|c|c|c|c|}
\hline Variables & Mean & $\begin{array}{c}\text { Mean } \\
\text { Difference }\end{array}$ & $r$-value & $\begin{array}{c}\text { Verbal } \\
\text { Interpretation }\end{array}$ & $p$-value & Decision & $\begin{array}{c}\text { Verbal } \\
\text { Interpretation }\end{array}$ \\
\hline Phonology & 75.93 & 12.54 & .204 & Low & .000 & Reject Ho & Significant \\
\hline Reading and writing skills & 85.86 & & & & & & \\
\hline Morphology & 74.92 & 13.46 & .555 & Moderate & .000 & Reject Ho & Significant \\
\hline Reading and writing skills & 85.86 & & & & & & \\
\hline Semantics & 73.15 & 15.23 & .401 & Moderate & .000 & Reject Ho & Significant \\
\hline Reading and writing skills & 85.86 & & & & & & \\
\hline Syntax & 72.02 & 16.36 & .355 & Low & .000 & Reject Ho & Significant \\
\hline Reading and writing skills & 85.86 & & & & & & \\
\hline
\end{tabular}

Note. $d f=279, p<.05$.

The table above shows the relationship between the areas of linguistic competence and academic performance in Reading and Writing Skills of the Grade 11 students. The relationship between phonology and 
academic performance in Reading and Writing Skills has a computed $r$-value of .204 and syntax with $r$-value .355 , which has the verbal interpretation of low correlation. On the other hand, Morphology and academic performance in Reading and Writing Skills got .555 and semantics with $r$-value .401 labelled as moderate correlation. This means that phonology and syntax has a relationship with the students' academic performance averagely. The table shows that morphology and semantics affects most in the academic performance of the students, since it has moderate correlation.

\section{Discussion}

\subsection{What is the level of linguistic competence of the students in terms of}

Phonology - The level which has the most number of frequencies is Fairly Satisfactory, which scales to 75-79. The results of the tests are not that so good in terms of the scale for it is ranging on 75-79, but, looking on the level which is fairly satisfactory made the researchers think of factors that affects the result of the linguistic competence test. Students may have that knowledge in phonology but considering the time they took the test and the previous things they have done, there may be confusion. With regard to the placement of stress in the word which may make them confused on what to place in the sentence. Also, confusion on how to syllabicate and pronounce words to determine the word that is pronounced and syllabicated the way the given word is. The spelling of the words is not a guarantee that words have the same pronunciation. Thus, students must have large pronunciation knowledge of words. Again, in the test given to the students, a part of the Phonology test items is that you will identify the correct word to place in the sentence. But, it is never easy, for the students need to consider the placement of stress in the word. This best explains why you should not just place a word in the sentence; you must to consider its way of pronunciation, because not all words have the same meaning and pronunciation.

Morphology - Most of the students fell under the Did Not Meet Expectation level, which scale ranges below 75. The researchers considered what had been told by the mentioned authors in the previous paragraph of this discussion. Students may be unconscious about morphology, that morphology includes affixes which was the topic used in the linguistic competence test.

Semantics - The level of students' linguistic competence in terms of semantics is Did Not Meet Expectations. In the linguistic competence test administered to the Grade 11 students, the test items in the area of Semantics consisted of synonyms and appropriate placing of the word in a given sentence. As what has been discussed by Fromkin and his fellow authors, words as used in the sentence contain the thought of the sentence. It simply implies that the correct usage, placement and selection of word/s have its impact to the meaning or to the thought of the sentence or context. In the study of Fromkin et al. (2010), they expressed that the meaning of the phrase or sentence is partially a function of the meanings of the words it contains. In other words, the use of the words that is in a sentence support the meaning of the sentence to which the respondents failed to recognize.

Syntax - Students' level of linguistic competence in terms of syntax is labelled as Did Not Meet Expectations. In the study by Anorico (2009), they covered the level of competency of students in areas of vocabulary, grammar and reading comprehension, which is part of syntax, to determine the level of performance or level of competency of third year BSED students of BSU College of Teacher Education. Their study shows that the majority of the Mathematics, Science and English major students of third year have the average level of performance in English Competency in areas of vocabulary and grammar, while in this study, it shows that majority of the subjects fell under the lowest level which is Did Not Meet Expectation. They also stated that in grammar, there is a need for more intensive teaching of grammar and provision of more grammatical exercises. Considering syntax as the most complicated among the four areas of linguistics, because it is the totality of what had been in the first three areas of linguistics, teachers and other concern personnel may establish activities or plan for the development of the students, linguistically. This is an indication that the respondents of this research 
Lozano, J. B., Ilagan, A., \& Maluluyon, L. J. A.

study have a low level of recognition of grammar and everything that follows.

\subsection{How may the levels of academic performance of the students in Oral Communication and Reading and}

Writing Skills be described?

The level of academic performance in Oral Communication and Reading and Writing Skills is both on the Very Satisfactory level. This implies that Grade 11 students gained much learning in Oral Communication and Reading and Writing Skills. As academic performance refers to how students deal with their studies, and with the result that Grade 11 students levelled under Very Satisfactory, the researchers must say that the Grade 11 students who took the linguistic competence test dealt well on their studies and they accomplished different tasks given by their teachers during the first semester of academic year 2016-2017.

\subsection{Are there any significant relationships between the levels of linguistic competence and academic}

performance of the students in Oral Communication and Reading and Writing Skills?

The linguistic competence and the academic performance in Oral Communication have a significant relationship. This means that the linguistic competence increases the academic performance also increases. In the discussion of Richard and Schimdt (2010), language proficiency is the degree of skill with which a person can use the language, such how well a person can read, write speak or understand language. This can be contrasted to the language achievement, which describes language ability as a result of learning. Proficiency may be measured through the use of proficiency test. This is true to Grade 11 students because their linguistic competence affects their academic performance.

The linguistic competence and the academic performance in Reading and Writing Skills have a significant relationship. This means that as the competence in linguistic increases, academic performance also increases. According to Magboo (2015), linguistic competence is a tool towards communication which is the symbiotic interaction of two or more persons. If communication is to occur a certain stimulus will be sent and received. Thus, the sender of the message must be efficient and proficient enough to convey the message as intelligible as possible so that it will be correctly understood and will make sense.

\subsection{Based on the findings, what linguistic enhancement activities may be proposed to improve student's \\ linguistic competence?}

This study proposed linguistic enhancement activities of Grade 11 students. This is designed to help teachers teach Linguistics to Grade 11 students to enhance their skills in every area of linguistics. The linguistic enhancement activities proposed by the researchers are as follows: Name that Thing, Spell and Say It, Speak Out, Contention by Words, Knowing Riddles, Word Stew, Word Steps, Personal Learning Dictionaries, Writing a Precis, Get in Order, Circulation and Flow of a Word, The Tool Box, Procedure Brainstorm, Function Cards, and, The A-Z Formidable Words.

\section{Conclusions and recommendations}

Upon thorough analysis of the gathered data during the conduct of this study, conclusions have been drawn.

D The linguistic competence of the Grade 11 students is on Did Not Meet Expectation level. This is the result upon getting the average of the four areas of linguistic competence. Phonology resulted to Fairly Satisfactory, while Morphology, Semantics and Syntax levelled Did Not Meet Expectations respectively.

$>$ The academic performance of the Grade 11 students in both Oral Communication and Reading and Writing Skills is on Very Satisfactory level. 
$>\quad$ There are significant relationships between the linguistic competence and academic performance in Oral Communication and Reading and Writing Skills of the Grade 11 students.

The enhancement activities may improve the linguistic competence of the students. The main targets of this Linguistic Enhancement Activities are as follows: to enhance the levels of Linguistic Competence and Academic Performance in Oral Communication and Reading and Writing Skills by increasing the quality of their outputs; to manifest understanding of the lessons through its actual use in the daily situation; to develop a sense of eagerness and willingness to adapt to the changes in the language; and to create outputs that demonstrate linguistic competence.

\subsection{Recommendations}

Recommendations of this study point towards students' development concerning linguistic competence.

$>\quad$ The school administrators may develop curricular programs which are essential to effective linguistic instruction; also they may furnish information on the level of competence of the students from which teachers may base their academic activities.

$>\quad$ The school coordinators may plan actions to unlock the areas where students are having a hard time with. After that, they may coordinate such with their respective fellow teachers.

$>\quad$ The teachers may develop their teaching strategy by considering the proposed linguistic enhancement activities in their teaching to produce linguistically competent students. They may integrate such proposed activities in the lessons they best fit in, this could help arouse student's eagerness and motivation to learn the lesson or the subject.

$>\quad$ The students may exert more efforts in studying if they are aware of the factors that affect their academic performance. Also, they may refer and utilize the research output proposed by the researchers to help them broaden and enrich their vocabulary, to improve how they compose or construct their own articles and write-ups, to confidently present their work either in written or oral form, and to develop and improve their linguistic competence in all four areas, together with the increase in their academic performance.

$>\quad$ The parents may serve as the constant partners of the teachers in watching over the students as they master the linguistic competence.

$>\quad$ The researchers may utilize the produced output, linguistic enhancement activities, to unfold and enhance students' competence in linguistics as they take their endeavor as teachers, English teachers.

The future researchers may conduct similar or comparable study that will deepen the findings of this study. They may develop research topics from this study, or something that would be of comparison to this research. They may likewise use this study as their reference to be cited on their would-be research study.

\section{References}

Acurantes, D. C. (2009). Improving your writing skills. Mandaluyong City: Books Atbp.

Agito, D. (2013). Learning styles of the first year college students at Sta. Teresa College and their effect on their academic performance in English: Basis for developing instructional materials [Masteral thesis]. Sta. Teresa College.

Anorico, M. K. R. (2009). Language competency of third year bachelor of secondary education students of Batangas State University [Masteral thesis]. Batangas State University.

Antenor, M. C. (2009). Module in curriculum development. University of Batangas.

Brantley, C. P., \& Miller, M. G. (2007). Effective communication for colleges. Mason, OH: Thomson. 
Lozano, J. B., Ilagan, A., \& Maluluyon, L. J. A.

Cabantac, B. M. C. (2011). Task-based dictation: A means of improving the language proficiency of college students of the Adamson university [Masteral thesis]. Philippine Normal University.

Cabral, A. D. (2012). Linguistic competency and academic performance in English of freshmen student in Sta. Teresa College: Basis for a proposed syllabus [Masteral thesis]. Sta. Teresa College.

Faarlund, J. T., Cappelen, H. W., \& Wilson, D. (2012). Linguistic competence. Retrieved from https://www.hf.uio.no/ifikk/english/research/csmn-research-projects/linugistic-competence/

Fromkin, V., Rodman, R., \& Hyams, N. (2010). An introduction to linguistic $\left(9^{\text {th }}\right.$ ed.). Cenage Learning.

Kashyap, A. (2012). Chomsky and linguistic competence. Retrieved from https://idleheresy.wordpress.com/2012/04/09/chomsky-linguistic-competence/

Koll, T. (2012). Better writing beyond period and commas. Lanham, Maryland: Rowman \& Littlefield Education.

Magboo, M. A. (2015). Linguistic competence and academic performance of grade 8 Students in San Pascual District, Division of Batangas [Masteral thesis]. Golden Gate College.

Pearson, J., Nelson, P., Titsworth, S., \& Harter, L. (2008). Human communication (3rd ed.). Boston, MA: McGraw Hill.

Richards, J. C., \& Schmidt, R. (2010). Longman dictionary of language teaching and applied linguistics (4th ed.). London: Longman.

Valdez, A. (2013). Descriptive research. United Kingdom: Demand Media. 